\title{
Kinetic Study of Esterification of Acetic Acid with n- butanol and isobutanol Catalyzed by Ion Exchange Resin
}

\author{
Amrit Pal Toor *, Mamta Sharma, Ghansyam Kumar, and R. K. Wanchoo \\ University Institute of Chemical Engineering \& Technology \\ Panjab University, Chandigarh-160014, INDIA
}

Received: 16th December 2010; Revised: 19th March 2011; Accepted: 7th April 2011

\begin{abstract}
Esters are an important pharmaceutical intermediates and very useful perfumery agents. In this study the esterification of acetic acid with n-butanol and iso-butanol over an acidic cation exchange resin, Amberlyst 15 were carried out. The effects of certain parameters such as temperature, catalyst loading, initial molar ratio between reactants on the rate of reaction were studied. The experiments were conducted in a stirred batch reactor in the temperature range of $351.15 \mathrm{~K}$ to $366.15 \mathrm{~K}$. Variation of parameters on rate of reaction demonstrated that the reaction was intrinsically controlled.The activation energy for the esterification of acetic acid with n-butanol and iso butanol is found to be $28.45 \mathrm{k} \mathrm{J} / \mathrm{mol}$ and $23.29 \mathrm{~kJ} / \mathrm{mol}$ respectively. C2011 BCREC UNDIP. All rights reserved.
\end{abstract}

Keywords: Heterogeneous catalysis; Esterification; acetic acid: Ion exchange resin; Amberlyst 15

\section{Introduction}

In the simplest terms, esters can be defined as the reaction products of acids and alcohols. Thousands of different kinds of esters are commercially produced for a broad range of applications. Within the realm of synthetic lubrication, a relatively small substantial family of esters has been found to be very useful in severe environment applications. The ester of acetic acid and isobutanol, namely, isobutyl acetate, finds wide industrial applications. Butyl acetates are used primarily as solvents in the lacquer and enamel industries. It is used in coatings, where its solvent capacity and its low relative volatility make it useful for adjustment of evaporation rate and viscosity. It is particularly useful as a solvent or thinner for acrylic polymers, vinyl resins, as reaction medium for adhesives, as solvent for leather dressings, and a process solvent in various applications and in cosmetic formulations [1-4].

Esterification of carboxylic acids with alcohols in presence of acid catalysts has been the subject of investigation by many research workers [5-12]. Salts like quaternary ammonium salt have been also used as a catalyst in esterification of carboxylic acids [13]. In few cases mesoporous silicas were functionalized with sulfonic acid groups; the resulting materials are excellent catalysts for formation of bisfurylalkanes and polyol esters [14].

Typical homogenous catalysts like $\mathrm{H}_{2} \mathrm{SO}_{4}, \mathrm{HCl}$ and $\mathrm{CISO}_{3} \mathrm{OH}$ are used but due to their miscibility with the reaction medium, separation becomes a problem. Therefore heterogeneous catalyst become an attractive alternative catalyst which is nonpolluting, non corrosive and has long activity life.

* Corresponding Author

E-mail: aptoor@yahoo.com (A. P. Toor ) 
The ion-exchange resin is a promising material for the replacement of the homogeneous acid catalysts. The solid type of material has good physical and chemical properties, and shows no corrosion as well as pollution, and show both high selectivity and thermal stability $[1,11]$.

Esterification of acetic acid with butanol has been carried out for several years now. One of the earliest systematic studies is by Othmer and coworkers, who investigated this reaction in the presence of sulphuric acid as a catalyst [15]. Alime has studied the liquid phase esterification of acetic acid with iso-butanol over ion exchange resins [16]. Ragini and his co-workers had studied the kinetics of esterification of diluted acetic acid with pure 2-ethyl-1-hexanol [17]. Cation exchange resin is considered to be an important catalyst for liquid-phase reactions like esterification, etherification, etc. [18].

Zheng and Zeng have studied the kinetics of esterification of acetic acid in the presence of a strong cation-exchange resin. They have investigated the influence of various parameters and proposed the second order rate equation [19, 20]. Meanwhile, the research on the esterification of acetic acid with propyl alcohol over heterogeneous catalyst, Dowex Monosphere 650 $\mathrm{C}$, has been reported [21], where the reaction mechanism was presented, and kinetic and thermodynamic parameters were calculated.

Liao and co-workers have also studied this reaction in the presence of solid acid Cationexchange resins [22-24]. Gangadwala et al [1] has also carried out the esterification of acetic acid with n-butanol in the presence of ion exchange resins as catalysts in the temperature range of 343.15 to $363.15 \mathrm{~K}$ at lower molar ratio keeping the other parameters constant. Despite several studies on this useful reaction, the work on high molar ratio is quite limited; as with the high molar ratio rate of reaction increases and reaction time also decreases. There are a number of studies related to the other esterification reactions catalyzed by ion exchange resins [25-34]

\section{Materials and Method}

\subsection{Material used}

Acetic acid, n-butanol and iso-butanol all were purchased from Merck with a claimed purity of $99.8 \%$. Sodium Hydroxide (s.d. fine chemicals ltd., Boisar), Phenolphthalein indicator, (Qualigens fine chemicals, Mumbai). All of them were used without further purification. Amberlyst -15 supplied by Rohm and Haas was used as catalyst and its relevant characteristics are summarized in Table 1[35].

\subsection{Experimental setup and procedure}

Esterification of acetic acid was studied in a three-necked glass reactor of $250 \mathrm{ml}$ capacity operating in a batch mode. A reflux condenser was used to avoid the loss of volatile compounds. The ion exchange resin was suspended in the reaction mixture with the help of stirrer. Acetic acid was used with the initial concentration of $1.93 \mathrm{~mol} / \mathrm{L}$ and the initial volume of the reaction mixture was approximately $100 \mathrm{~mL}$. Predetermined amount of acetic acid and catalyst were charged into the reactor and heated to the desired temperature. Temperature inside the reactor was controlled within the accuracy of $\pm 0.5 \mathrm{~K}$. After the desired temperature has been reached, butanol was added into the reactor at the same temperature and this was taken as zero time for a run. All of the reactants charged in the reactor were volumetrically measured. The progress of the reaction was followed by withdrawing samples small enough to consider them negligible compared to the volume of the reaction mixture at regular intervals. Samples were taken periodically and titrated against $1 \mathrm{~N}$ std $\mathrm{NaOH}$ solution using phenolphthalein as an indicator.

\section{Results and Discussion}

\subsection{Kinetic modeling}

The general reaction rate expression for this reaction can be written as:

$$
\mathrm{A}+\mathrm{B} \Leftrightarrow \mathrm{C}+\mathrm{D}
$$

Where $\mathrm{A}=$ acetic acid, $\mathrm{B}=$ butanol, $\mathrm{E}=$ butyl acetate and $\mathrm{W}=$ water

Table 1. Physicochemical properties of Amberlyst 15

\begin{tabular}{cc}
\hline Skeleton & Styrene -Divinyl benzene \\
\hline Type & strong acid \\
Structure & Macro reticular \\
Functional group & Sulfuric $\left(\mathrm{SO}_{3} \mathrm{H}\right)$ \\
Ionic form & Hydrogen \\
Max.operating temp. & $393 \mathrm{~K}$ \\
Particle size & $0.600-0.685 \mu \mathrm{m}$ \\
Internal porosity & 0.36 \\
Concentration of acid & $4.53 \mathrm{~m} \mathrm{equiv/g.} \mathrm{of} \mathrm{dry} \mathrm{resin}$ \\
sites & $1410 \mathrm{Kg} / \mathrm{m}^{3}$ \\
\hline
\end{tabular}


At steady state the rate of mass transfer per unit volume of the liquid phase can be expressed as [5]:

$\mathrm{r}_{\mathrm{A}}=\mathrm{k}_{\mathrm{LSA}} \alpha_{\mathrm{P}}\left[\mathrm{C}_{\mathrm{A}}-\mathrm{C}_{\mathrm{AS}}\right]$

which is the rate of diffusion of A from bulk liquid phase to the catalyst surface and :

$\mathrm{r}_{\mathrm{A}}=\mathrm{k}_{\mathrm{LSB}}$ aP $\left[\mathrm{C}_{\mathrm{B}}-\mathrm{C}_{\mathrm{BS}}\right]$

which is the rate of diffusion of B from bulk liquid phase to the catalyst surface [5]. The rate of surface reaction per unit volume, $\left(-r_{A}\right)$ in presence of intraparticle diffusion [5] can be expressed as:

$$
\eta_{A}\left(k m o l L^{-1} S^{-1}\right)=\frac{\eta k_{1} w\left[C_{A}\right]\left[C_{Z}\right]}{1+K_{A}\left[C_{A}\right]+K_{B}\left[C_{\Xi}\right]}
$$

Equation 4 is a Langmuir-Hinshelwood-HougenWatson type model (LHHW). Adsorption or desorption steps are unimportant in this case because catalyst used is a macro porous ion exchange resin and the reactants are able to diffuse into pores and the products diffuse out without any resistance [5].

Hence Equation 4 can be replaced by power law model and $\eta$ is unity for catalyst particle size less than $700 \mu \mathrm{m}$ [Table 1].

$$
\mathrm{r}_{\mathrm{A}}=\mathrm{k}_{1} \mathrm{w}\left[\mathrm{C}_{\mathrm{A}}\right]\left[\mathrm{C}_{\mathrm{B}}\right]
$$

When external and internal resistances to mass transfer are absent, the following holds [5]

$$
\frac{1}{k_{1}(w)\left[C_{A}\right]\left[C_{B}\right]}>>\frac{1}{k_{L S A} a_{S}\left[C_{A}\right]} \text { and } \frac{1}{k_{L S B} a_{S}\left[C_{B}\right]}
$$

Then the surface reaction is the controlling mechanism and the overall rate of the reaction will be the same as given by the surface reaction, i.e.

$$
\int_{0}^{X A} \frac{d X_{A}}{\left(1-X_{A}\right)\left(M-X_{A}\right)}=C_{A 0} w k_{1} \int_{0}^{t} d t
$$

After integrating Equation (7) becomes:

$$
\ln \frac{M-X_{A}}{M\left(1-X_{A}\right)}=k_{1} C_{A 0} w(M-1) t
$$

Putting $\mathrm{C}_{\mathrm{AW}}(\mathrm{M}-1) \mathrm{k}_{1}=\mathrm{k}$ in equation (8) we get: $\ln \frac{M-X_{A}}{M\left(1-X_{A}\right)}=k t$

Plotting the left hand side of Equation (9) versus time, a straight line with a slope $\mathrm{k}$ is obtained.

\subsection{Elimination of mass transfer resistance}

Previous studies pointed that external diffusion does not usually control the overall rate in the reactions catalyzed by ion exchanges resin unless the agitation speed is very low or the reaction mixture is very viscous and intraparticle diffusion resistances of the reactant in the ion exchange resins are not so important $[6-8,18]$. Hence all the experiments were conducted with the ion exchange resin that was supplied by manufacture (Rohm and Hass Co.) and at a fixed $500 \mathrm{rpm}$ for all the experiments.

\subsection{Effect of catalyst loading}

The effect of catalyst loading on esterification rate is shown in figures 1 to 2 . The catalyst loading was varied from 4 to $11 \%\left(22.43 \mathrm{~kg} / \mathrm{m}^{3}\right.$ to $\left.139.6 \mathrm{~kg} / \mathrm{m}^{3}\right)$ for esterification reactions of acetic acid with $\mathrm{n}$ butanol and isobutanol while keeping the other parameters constant(molar ratio 1:5 and temperature $366.15 \mathrm{~K})$. The conversion of acetic acid as a function of time with different catalyst loadings are shown in Figure 1 for nbutanol at $366.15 \mathrm{~K}$ and Figure 2 for isobutanol at $366.15 \mathrm{~K}$. It was found that with an increase in catalyst loading the conversion of acid increases with the increase in the active sites. At higher catalysts loading the rate of mass transfer is high and therefore there is no significant increase in the rate [30]. Gangadwala et al [1] have achieved $60 \%$ conversion using $20 \mathrm{~g} / \mathrm{g} \mathrm{mol}$ of acetic acid in 50 minutes with 1:1 molar ratio of acetic acid to $n$

\begin{tabular}{|c|c|c|}
\hline $\begin{array}{l}\text { Catalyst load- } \\
\text { ing }\left(\mathrm{kg} / \mathrm{m}^{3}\right)\end{array}$ & $\begin{array}{c}\mathbf{k} \text { for } \mathrm{n} \text {-butanol } \\
\left(\mathrm{min}^{-1}\right)\end{array}$ & $\begin{array}{c}\text { k for Iso-butanol } \\
\left(\mathrm{min}^{-1}\right)\end{array}$ \\
\hline 22.43 & $0.7 \times 10^{-2}$ & $1.2 \times 10^{-2}$ \\
\hline 67.3 & $1.5 \times 10^{-2}$ & $3.3 \times 10^{-2}$ \\
\hline 89.7 & $1.9 \times 10^{-2}$ & $4.5 \times 10^{-2}$ \\
\hline 112.2 & $2.6 \times 10^{-2}$ & $5.5 \times 10^{-2}$ \\
\hline 134.6 & $3.5 \times 10^{-2}$ & $6.7 \times 10^{-2}$ \\
\hline
\end{tabular}
-butanol whereas by increasing the molar ratio up to $1: 5$ the conversion up to $80 \%$ in same time

Table 2. Rate constant values for n-butanol and iso-butanol 
seen that the conversion of acetic acid increases with increasing the initial molar ratio of alcohols to acetic acid. Gangadwala et al [1] have also reported that conversion increases from $50 \%$ to $80 \%$ in 90 minutes from 1:1 to 1:3 molar ratio of acetic acid to n-butanol. By increasing the molar ratio up to $1: 10$ the conversion was achieved up to $92 \%$ in 75 minutes and using $79.4 \%$ of catalyst used by Gangadwala [1]. The results observed for the effect of initial molar ratio of alcohols to acetic acid indicated that the conversion of acid can be enhanced by using a large excess of alcohols, which is consistent with the results of Sanz et al [30] who studied the esterification of acetic acid with isopropanol.

\subsection{Effect of Temperature}

The results from the esterification of acetic acid with $\mathrm{n}$ butanol and isobutanol over Amberlyst 15 at different temperatures and with a fixed initial molar ratio $1: 5$ of the reactant are displayed in Figures 8 and 9. It was seen that the

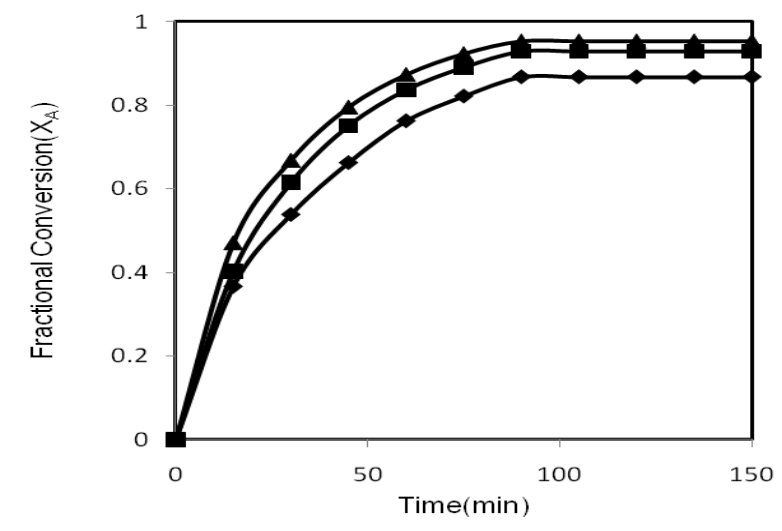

Figure 6. Conversion $\mathrm{X}_{\mathrm{A}}$ versus Time for different molar ratio of (AA: NB) for $112.2 \mathrm{~kg} / \mathrm{m}^{3}$ catalyst loading $366.15 \mathrm{~K}, \times 1: 10, \mathbf{\Lambda} 1: 5, \mathbf{\square} 1: 3$,

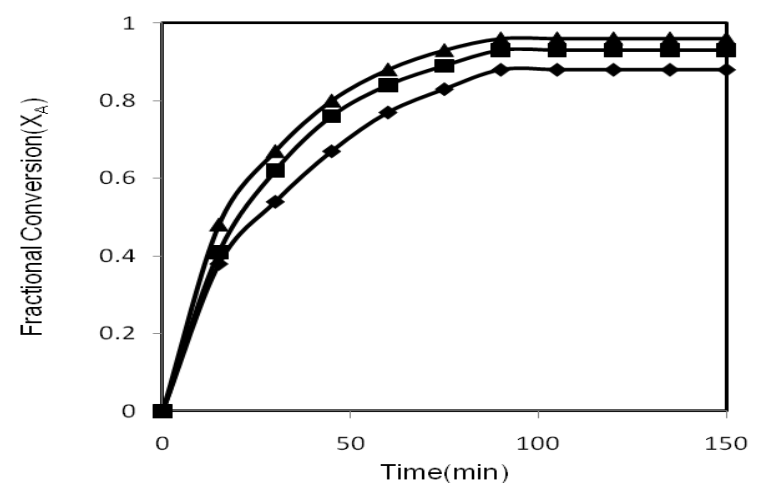

Figure 7. $\mathrm{X}_{\mathrm{A}}$ versus Time for different molar ratio for (AA: IB) for $112.2 \mathrm{~kg} / \mathrm{m}^{3}$ catalyst loading at 366.15K. , ×1:10, $\boldsymbol{\Delta} 1: 5, \mathbf{\square} 1: 3$, conversion increases with temperature, indicating absence of mass transfer effects. Same trend was observed by Roy and Bhatia [31] for the esterification of acetic acid with benzyl alcohol over Amberlyst 15. Both esterification reactions were carried out in the temperature range from 351.15 to $366.15 \mathrm{~K}$. The study of the effect of temperature is very important since it is useful to calculate activation energy of the reaction. The observed reaction rate constants (k) data at different temperatures were fitted to the Arrhenius-type equation (Eq.13) and the model parameters, ko (frequency factor) and $\mathrm{E}_{\mathrm{o}}$ (activation energy), were determined using linear regression technique.

$$
k=k_{0} \exp \left(\frac{-E_{0}}{R T}\right)
$$

Activation energy, $\mathrm{E}_{0}$ was found to be $28.45 \mathrm{~kJ} /$ mol and $23.29 \mathrm{~kJ} / \mathrm{mol}$ for n-butanol and isobutanol respectively. frequency factor, ko was found to be $0.033 \mathrm{~min}^{-1}$ and $0.082 \mathrm{~min}-1$ for $\mathrm{n}$ butanol and iso-butanol respectively. A plot of -ln $\mathrm{k}$ versus 1000/T at constant acid and alcohol concentrations, gives a straight line with slope of (E/R) as shown in Fig 10.

\section{Conclusion}

In this study the kinetics of the esterification of acetic acid with n-butanol and isobutanol catalyzed by Amberlyst 15 was experimentally investigated. The reaction rate was found to

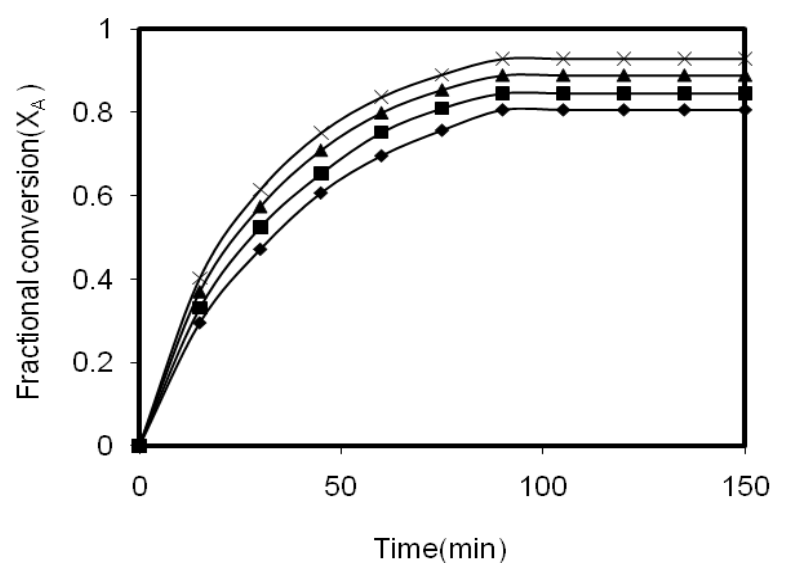

Figure 8. $X_{A}$ versus Time for different temperatures for (AA: NB) for $112.2 \mathrm{~kg} / \mathrm{m}^{3}$ catalyst loading at molar ratio $1: 5, \times 366.15 \mathrm{~K}, \mathbf{\Delta} 361.15 \mathrm{~K}, \quad 356.15$ $\mathrm{K}, 351.15 \mathrm{~K}$ 
with catalyst $5.3 \mathrm{~g} / \mathrm{g} \mathrm{mol}$ of acetic acid was achieved.

The rate constants for both the reactions were obtained by plotting LHS of Equation (9) vs. $t$ as shown in Figures 3 and 4, The values of $\mathrm{k}$ are given in table 2 for both n-butanol and isobutanol. It is also observed from Figure 5 and Table 2 that the rate constant $\mathrm{k}$ for isobutanol is higher than $\mathrm{n}$ -butanol. The $\mathrm{k}$ values were plotted against weight of the catalyst and it was observed that with increase in $\mathrm{w}$ there was linear increase in $\mathrm{k}$ (Fig 5).

\subsection{Effect of Molar Ratio}

To investigate the effect of the initial molar ratio of alcohols to acetic acid on conversion of acetic acid, the initial molar ratio was 1:3, 1:5 and 1:10 for $\mathrm{n}$ butanol and isobutanol both. The

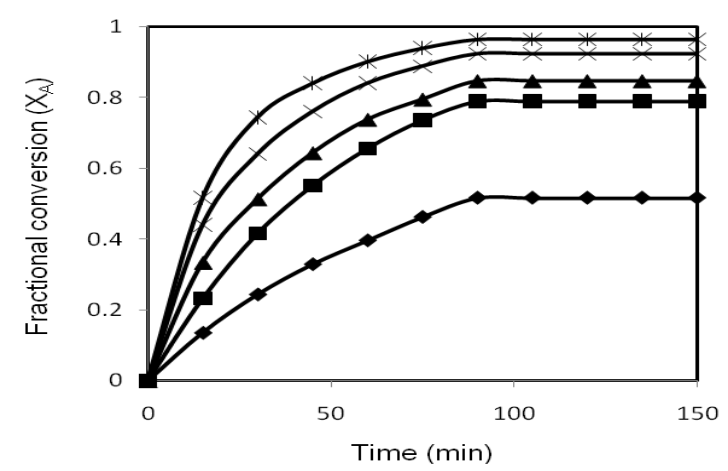

Figure 1. Effect of catalyst loading $\left(\mathrm{kg} / \mathrm{m}^{3}\right)$.

Temperture: $366.15 \mathrm{~K}$, molar ratio(AA: NB): 1:5, a $139.6, \times 112.2, \boldsymbol{\Delta} 89.7, \square 67.3, \diamond 22.43$.

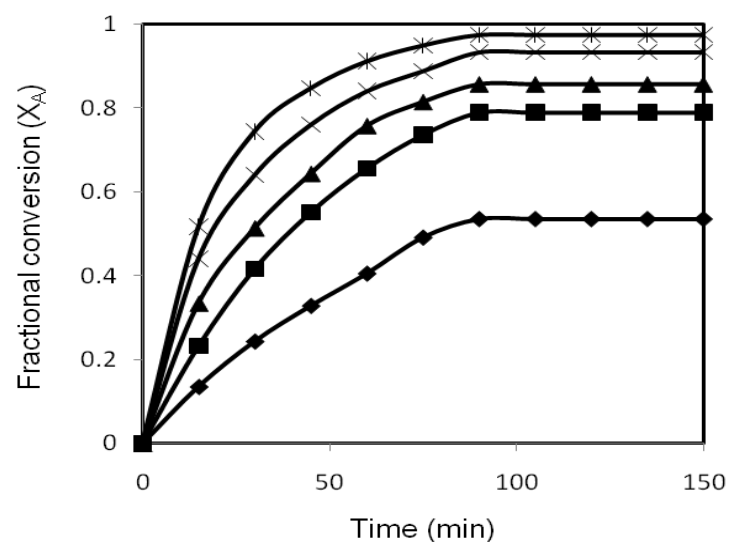

Figure 2. Effect of catalyst loading $\left(\mathrm{kg} / \mathrm{m}^{3}\right)$.

Temperture: $366.15 \mathrm{~K}$, molar ratio(AA: IB): 1:5, $\times 112.2$, a $139.6, \boldsymbol{\Delta} 89.7, \square 67.3, \diamond 22.43$

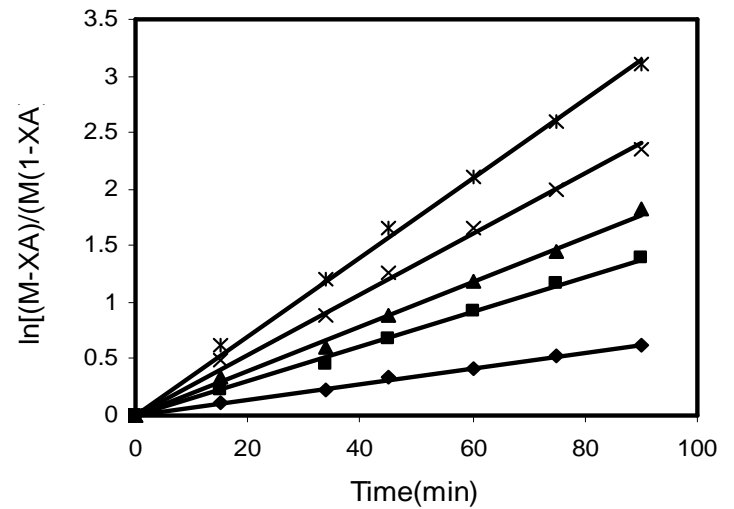

Figure 3. Effect of catalyst loading $\left(\mathrm{kg} / \mathrm{m}^{3}\right)$. L.H.S of eq. 9 vs. Time. Temperture: $366.15 \mathrm{~K}$, molar ratio(AA: NB): 1:5, ,×112.2, a $139.6, \boldsymbol{\Delta} 89.7$, $67.3, \diamond 22.43$

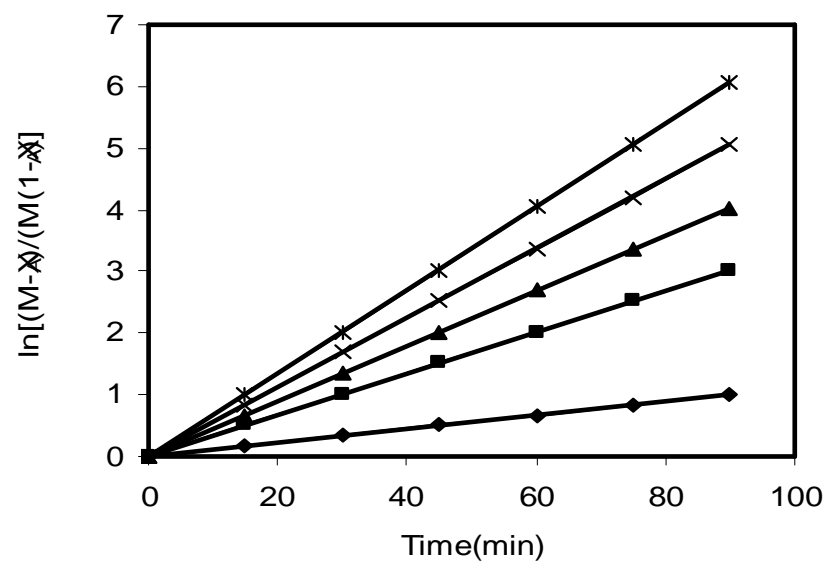

Figure 4. Effect of catalyst loading $\left(\mathrm{kg} / \mathrm{m}^{3}\right)$. L.H.S of eq. 9 vs. Time. Temperture: $366.15 \mathrm{~K}$, molar ratio(AA: IB): 1:5, ,×112.2, a $139.6, \mathbf{\Delta} 89.7$,

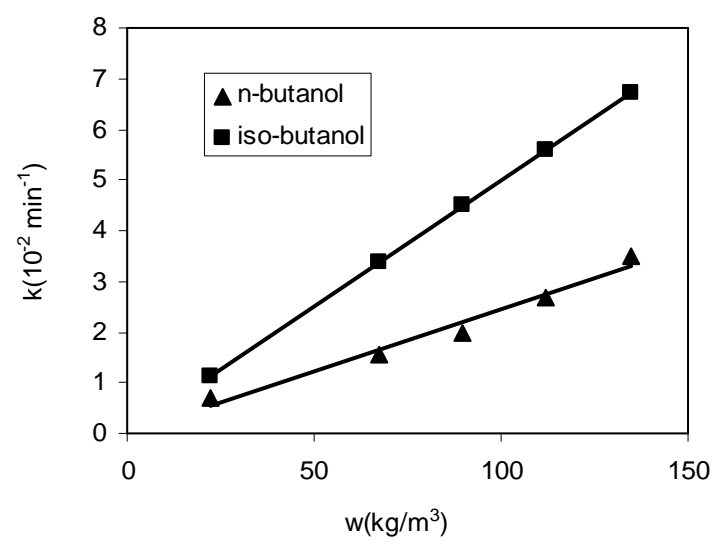

Figure 5. Effect of catalyst loading on rate constant (k) at Temperature: $366.15 \mathrm{~K}$, molar ratio, $1: 5$ 


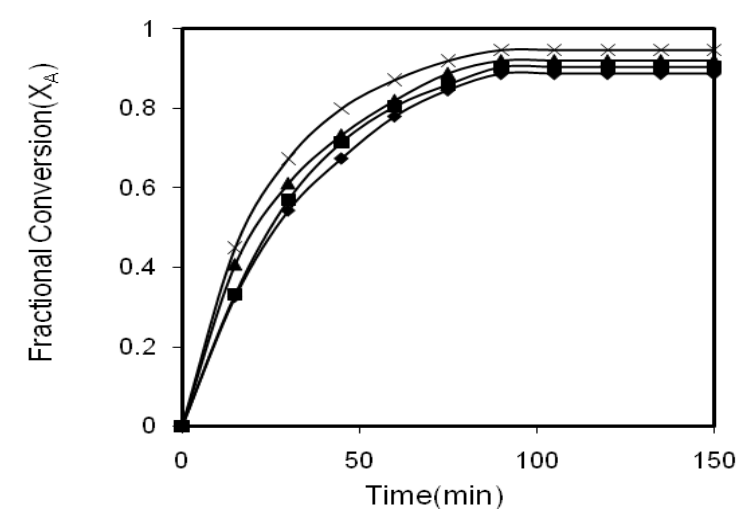

Figure 9. $\mathrm{X}_{\mathrm{A}}$ versus Time for different temperatures for (AA: IB) for $112.2 \mathrm{~kg} / \mathrm{m}^{3}$ catalyst loading at molar ratio $1: 5, \times 366.15 \mathrm{~K}$, $361.15 \mathrm{~K}, 356.15 \mathrm{~K}, 351.15 \mathrm{~K}$

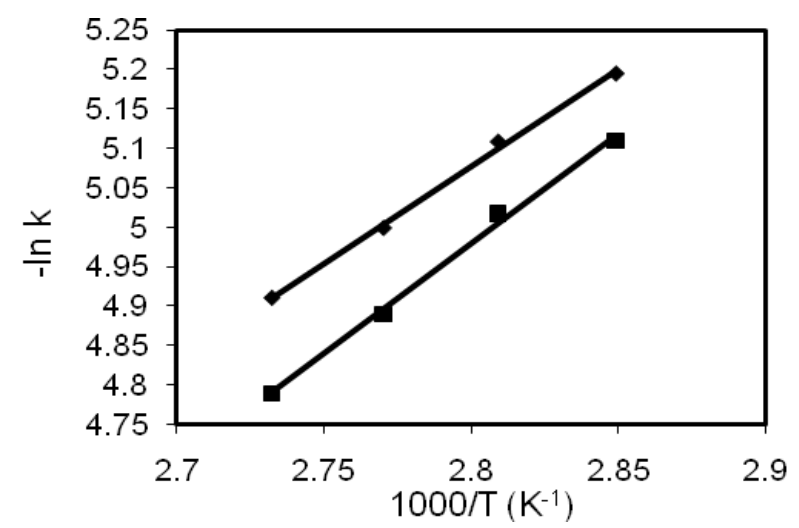

Figure10. Arrhenius plot of the rate constant, -NB, $\bullet \mathrm{IB}$

increase with increasing catalyst loading, temperature and molar ratio. The LHHW model was used to simulate the experimental data. Reactivity of n-butanol and isobutanol towards the synthesis of butyl acetate via the esterification of acetic acid with these alcohols was checked. Comparison of these alcohols shows that activation energy reduces from $28.45 \mathrm{~kJ} / \mathrm{mol}$ in case of $\mathrm{n}$ butanol to $23.29 \mathrm{~kJ} / \mathrm{mol}$ in case of isobutanol.

\section{Nomenclature}
AA Acetic acid
B Butanol
NB n-Butanol
IB Iso-butanol
$\mathrm{k} \quad$ Rate constant for esterification

\begin{tabular}{|c|c|}
\hline & reaction, $\min ^{-1}$ \\
\hline $\mathrm{k}_{1}$ & Second order rate constant, min- 1 mol-1 g- 1 \\
\hline $\mathrm{C}_{\mathrm{A}}$ & $\begin{array}{l}\text { Concentration of } \mathrm{AA} \text { in the bulk at time } \\
\mathrm{t}=0(\mathrm{~mol} / \mathrm{L})\end{array}$ \\
\hline $\mathrm{C}_{\mathrm{B}}$ & Concentration of B in the bulk $(\mathrm{mol} / \mathrm{L})$ \\
\hline $\mathrm{C}_{\mathrm{AS}}$ & $\begin{array}{l}\text { Concentration of AA at the surface of the } \\
\text { catalyst, }(\mathrm{mol} / \mathrm{L})\end{array}$ \\
\hline $\mathrm{C}_{\mathrm{BS}}$ & $\begin{array}{l}\text { Concentration of B at the surface of the } \\
\text { catalyst, }(\mathrm{mol} / \mathrm{L})\end{array}$ \\
\hline M & Molar ratio of alcohol to acid \\
\hline $\mathrm{X}_{\mathrm{A}}$ & Fractional conversion of AA \\
\hline $\mathrm{w}$ & Catalyst loading, $\left(\mathrm{kg} / \mathrm{m}^{3}\right)$ \\
\hline $\mathrm{t}$ & Time, minutes \\
\hline $\mathrm{T}$ & Temperture, ${ }^{\circ} \mathrm{C}$ \\
\hline $\mathrm{V}$ & Volume of the reaction mixture $(\mathrm{L})$ \\
\hline $\mathrm{K}$ & Equilibrium rate constant \\
\hline $\mathrm{K}_{\mathrm{w}}$ & Adsorption rate constant for water \\
\hline $\mathrm{K}_{\mathrm{B}}$ & Adsorption rate constant for alcohol \\
\hline$k_{0}$ & Frequency factor $\left(\min ^{-1}\right)$ \\
\hline$E_{1}$ & Activation energy $\left(\mathrm{kJmol}^{-1}\right)$ \\
\hline $\mathrm{k}_{\mathrm{LSA}}$ & $\begin{array}{l}\text { Solid liquid mass transfer coefficient for } \\
\text { AA, m/s }\end{array}$ \\
\hline $\mathrm{k}_{\mathrm{LSB}}$ & $\begin{array}{l}\text { Solid liquid mass transfer coefficient for } \\
\mathrm{NB} \text { and IB, } \mathrm{m} / \mathrm{s}\end{array}$ \\
\hline$\dot{b}_{\mathrm{p}}$ & $\begin{array}{l}\text { Surface area per unit volume of the } \\
\text { catalyst, } \mathrm{m}^{2} / \mathrm{m}^{3}\end{array}$ \\
\hline$\Gamma$ & Effectiveness factor, Dimensionless \\
\hline
\end{tabular}

\section{References}

[1] Gangadwala, J., Manker, S., Mahajani, 2003, Esterification of acetic acid butanol in the presence of ion-exchange resins as catalysts, Ind. Eng. Chem. Res., 42:2146-2155.

[2] Grob, S., Hasse, H., 2006, Thermodynamics of Phase and Chemical Equilibrium in a Strongly Nonideal Esterification System, Ind. Eng. Chem. Res., 45: 1869-1874.

[3] Yadav, G.D., Rahuman, M.S.M., 2003, Synthesis of fragrance and flavor grade esters: activities of different ion exchange resins and kinetic studies, Clean Techn. Environ, 5:128ї 135.

[4] Liu, K., Z. Tong, L., Liu, X., Feng, J., 2005, Separation of organic compounds from water by reactive distillation, J. Membrane Sci., 193 İ 201. 
[5] Yadav, G. D., Kulkarni, H. B., 2000, Ion exchange resin catalysis in the synthesis of isopropyl lactate, React. Funct. Polym., 44:153-165.

[6] Seo,Y., Hong, W., 2000, Effects of Operation Variables on the Recovery of Lactic Acid in a Batch Distillation Process with Chemical Reactions, J. Chem. Eng. Jpn, 33:128-133,

[7] Altiokka, M.R., Citak, A., 2003, Kinetics study of esterification of acetic acid with isobutanol in the presence of amberlite catalyst, Appl. Catal. A: Gen. 239: 141-148.

[8] Teo. H.T.R., Saha, B., 2004, Heterogeneous catalysed esterification of acetic acid with isoamyl alcohol: kinetic studies, J. Catal. 228:174-182

[9] Zhang.Y., Ma. L, Yang. J., 2004, Esterification of acetic acid with methanol over ion exchange resins by reactive distillation, React. Funct. Polym. 61:101 $-114$

[10] Liu, Y., Lotero, E., Goodwin, Jr., 2006, Kinetics esterification of lactic acid with ethanol catalyzed by cation exchange resin, J.Catal.,242:272-286.

[11] Ali, S. H., Merchant, S. Q., 2006, Kinetics of the esterification of acetic acid with 2-propanol: Impact of different acidic cation exchange resins on reaction mechanism, Int. J. Chem. Kinet., 38:593612

[12] Mcketta John J., 1983, Encyclopedia of Chemical Processing and Design, V-19

[13] Jihad, D., Yoel, S., Kamal, K., Georges, B., Andre, L., Esterification of carboxylic acids by benzyl chloride using quaternary ammonium salts, J. Chem. Soc. Chem. Commun., 1991, 853-854

[14] Wim, M., Van, R., Dirk, E., De, V., Bert, F.,Sulfonic acid functionalized ordered mesoporous materials as catalysts for condensation and esterification reactions, Chem. Commun., 1998, 317-318

[15] Othmer, D. F. Leyes, C. E.,1945, Continuous esterification of butanol and acetic acid, Kinetic and distillation considerations, Ind. Eng. Chem. Res.,37: 968-971

[16] Alime, I., Feyza, B., 2007, Kinetics of synthesis of isobutyl propionate over Amberlyst 15, React. Funct. Polym., 67:1458-1464

[17] Ragini,V., Bianchi, C. L., Pirola, C., 2007, Kinetics of esterification of diluted acetic acid with pure 2ethyl 1-hexanol, Chem. Eng. J., 131:257-262

[18] Chakrabarty, A., Sharma, M. M., 1993, Cationic exchange resins as catalyst, React. Polym., 20:1-45.
[19] Zheng, R., Zeng, J., 1997, Catalyst for butyl acetate using strong acidic cation-exchange resin. Xiamen Daxue Xuebao, Ziran Kexueban, Chem. Abstr. 127, 36:67-70;

[20] Zheng, R., Zeng, J., 1998, Kinetics of esterification of acetic acid and n-butanol on strong cationexchange resin. Xiamen Daxue Xuebao, Ziran Kexueban, Chem. Abstr. 129, 951425, 37: 224-227

[21] H.I. Bart, Kinetics of esterification of acetic acid with propyl alcohol by hetero- geneous catalysis, Int. J. Chem. Kinet. 28 (1996) 649ї 656.

[22] Liao, A., Tong, Z., 1995, Synthesis of n-butyl acetate catalyzed by Amberlyst, Chem. React. Eng. Tech. (China), 11 (4): 406-408

[23] Liao, S., Zhange, X., 1997, Study on esterification catalyzed by solid acid catalyst (II). Kinetics and mechanism of liquid-phase Esterification, J. S. China Univ. Tech. (Nat.Sci.), 25(11):88-92

[24] Liao, S., Xu, B., Li, Z., 1993, Catalysis of solid acid catalyst for esterification (I) preparation and characterization of the catalyst, J. Mol. Catal. (China), 7(6):475-478 .

[25] Chakrabarti, A., Sharma, M. M., 1993, Cation ion exchange resins as catalyst. React. Polym., 20(1), 45-51.

[26] Arabi, M., Amini, M.M., Abedini, M., Nemanti, A., Alizadeh, M., 2003, Esterification of phthalic anhydride with 1-butanol and 2-butanol ethylhexanol catalyzed by heteropolyacids., J. Molec. Catal. A: Chem., 200:105-110 .

[27] Emine, S., Sami, F., 2009, Kinetic study of the esterification of acetic acid with butanol catalyzed by sulfatedzirconia, React. Kinet. Mech. Cat., 99:125-134.

[28] Yadav,G., Thathagar, M., 2002, Esterification of maleic acid with ethanol over Cation exchange resin catalysts, React. Funct. Poly., 52:99-110

[29] Mazzotti, M., Neri, B., Gelosa, D., Kruglov, A., Morbidelli, M., 1997, Kinetics of Liquid-Phase Esterification Catalyzed by Acidic Resins, Ind. \& Eng. Chem. Res., 36(1):3-10.

[30] Sanz M. T., Gmehling J., 2006, Esterification of acetic acid with isopropanol coupled with pervaporation: Part I: Kinetics and pervaporation studies. Chem. Eng. J. 123:1-8.

[31] Roy,R.,Bhatia,S., 1987,Kinetics of esterification of benzyl alcohol with acetic acid catalysed by cationexchange resin (Amberlyst-15), J. Chem. Tech. Biotechnol, 37:1-10.

[32] Pöpken, T., Götze, L., Gmehling, J., 2009, Reaction Kinetics and Chemical Equilibrium of 
Homogeneously and Heterogeneously Catalyzed Acetic Acid Esterification with Methanol and Methyl Acetate Hydrolysis, Ind. Eng. Chem. Res, 39(7):2601-2611.

[33] Lee, M.-J., Chiu, J., Lin, H., 2002, Kinetics of

Catalytic Esterification of Propionic Acid and nButanol over Amberlyst 35, Ind. Eng. Chem. Res, 41(12): 2882-2887.
[34] Lee, M.-J., Wu, H.-T., Lin, H., 2000,Kinetics of Catalytic Esterification of Acetic Acid and Amyl Alcohol over Dowex, Ind. Eng. Chem. Res., 39(11): 4094-4099.

[35] Ayyappan K. R., Toor A. P., Gupta R., Bansal A., Wanchoo R. K., ñCatalytic hydrolysis of Ethyl Acetate using cation exchange resin (Amberlyst 15):A kinetic studyò, Bull. Chem. React. Eng. Catal. 2009, 4(1), 16-22. 